\title{
Взаимосвязь тепловой проводимости импульсно нагретого раствора с его объемом смешения
}

\author{
(ㄱ Д.В. Волосников, И.И. Поволоцкий, П.В. Скрипов \\ Институт теплофизики УрО РАН, Екатеринбург, Россия \\ T E-mail: pavel-skripov@bk.ru
}

Поступило в Редакцию 10 марта 2021 г.

В окончательной редакции 16 июля 2021 г.

Принято к публикации 30 июля 2021 г.

\begin{abstract}
В опытах по импульсному нагреву зонда в растворах различной природы установлен факт взаимосвязи тепловой проводимости раствора с его объемом смешения. Полученные результаты согласуются с данными, свидетельствующими о появлении дополнительного (относительно аддитивных значений) теплового сопротивления в жидкости при добавлении в нее второго компонента. Опыты выполнены при существенном расширении области изменения значений объема смешения и температуры, включая не вполне устойчивые состояния, кратковременно перегретые относительно температуры равновесия жидкость-пар и/или жидкость-жидкость раствора.
\end{abstract}

Ключевые слова: импульсный нагрев, тепловая проводимость, растворы, объем смешения.

DOI: 10.21883/PJTF.2021.22.51721.18761

Предметом исследования является выяснение взаимосвязи тепловой проводимости импульсно нагретого раствора и его избыточных свойств при исходной температуре. Измерения плотности и расчет объема смешения - хорошо отработанная процедура, не требующая дорогостоящего оборудования. Исследование переноса тепла растворами, особенно их теплопроводности, представляет собой серьезную экспериментальную задачу ввиду необходимости максимально точного приближения условий эксперимента к расчетным моделям $[1,2]$. С учетом многообразия растворов, применяемых в технике, и сложности определения их теплофизических свойств [3] важно найти основание для быстрой оценки характерных черт тепловой проводимости (молекулярного переноса теплоты) при известных значениях объема смешения. В первую очередь такая оценка востребована для кратковременно перегретых состояний [4-6], свойственных процессам с мощным тепловыделением.

Мотивацией данного исследования послужили данные о появлении дополнительного сопротивления переносу тепла (теплового сопротивления) в жидкости при добавлении в нее второго компонента. Наиболее глубоко они были обсуждены в работах Филиппова и Кравчуна $[7,8]$. В этих работах было сделано предположение, что источником дополнительного теплового сопротивления служит рассеяние фононов, обусловленное флуктуациями концентрации, а одним из главных факторов является величина объема смешения, выраженная через соотношение плотности раствора и ее аддитивного значения. Авторы работ $[7,8]$ подтвердили свои выводы результатами опытов на растворах с близкими значениями теплопроводности компонентов, имевших сравнительно небольшие значения объема смешения (на уровне $\left.0.01-0.2 \mathrm{~cm}^{3} / \mathrm{mol}\right)$. В силу ряда обстоятельств [9] эти опыты не были распространены на растворы с существенным отклонением от идеального закона, в том числе на растворы с отрицательными значениями объема смешения.

Цель данного исследования - получение нового знания о тепловой проводимости растворов с большими (по модулю) значениями объема смешения $v^{E}$ в широкой области изменения температуры, включая область не вполне устойчивых состояний, кратковременно перегретых относительно температуры равновесия жидкость-пар $T_{s}$ или жидкость-жидкость $T_{l l}$ раствора, недоступную для стационарных методов измерения.

Исходя из цели работы объектами исследования служили водные растворы полиэтилен- и полипропиленгликолей (ПЭГ и ППГ соответственно), а также растворы фторорганических жидкостей (ФОЖ) с предельными и непредельными углеводородами, имеющие большие (по модулю) значения $v^{E}$. Подбор компонентов обеспечил получение существенно неидеальных растворов с объемами смешения $v^{E}$ от -2 до $6 \mathrm{~cm}^{3} / \mathrm{mol}$ и соотношением плотностей компонентов $\rho_{1} / \rho_{2}$ от 1.1 до 2.7 .

В качестве инструмента исследования применен метод управляемого импульсного нагрева проволочного зонда в режиме изотермического воздействия [10], позволяющий ставить опыты не только в температурной области устойчивых состояний, но и при кратковременном (относительно характерного времени „включения“ механизма конвекции) перегреве жидкости.

Суть данного режима состоит в создании кратковременных квазиизотермических условий для импульсно нагреваемого зонда в веществе $T\left(t>t_{1}\right)=T_{s t}(t) \approx$ const при соответствующем регулировании мощности его нагрева. В опыте измеряются значения падения напряжения на зонде и образцовом (токовом) резисторе, включенном последовательно зонду. По первичным данным 


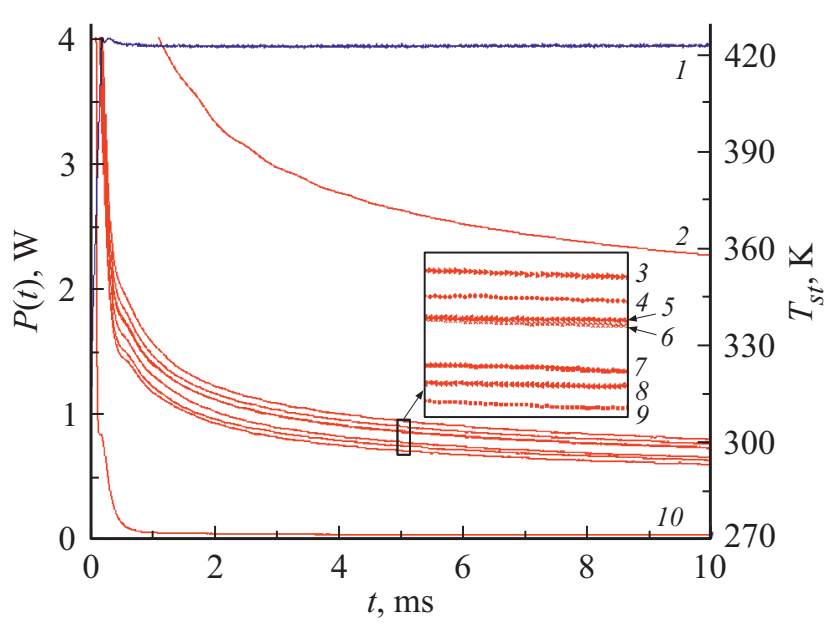

Рис. 1. Сопоставление измеренных значений мощности $P(t)$ при температуре $T_{s t}=423 \mathrm{~K}$, представленной кривой 1 , для различных образцов: 2 - вода; 3 - пропиленгликоль; $4-$ ПЭГ-200; 5 - ПЭГ-400; 6 - ПЭГ-600; 7 - дипропиленгликоль; 8 - трипропиленгликоль; $9-$ ППГ-425; $10-$ воздух, $660 \mathrm{~Pa}$.

опыта с привлечением данных стандартной градуировки платиновых термометров рассчитываются значения температуры зонда $T_{s t}(t)$ и электрической мощности $P\left(t ; T_{s t}\right)$, необходимой для ее поддержания (рис. 1). Далее рассчитываются средняя (по поверхности зонда) плотность теплового потока и мгновенный коэффициент тепловой проводимости $K_{T}(t)$ (как основная переменная в опытах с мощным тепловыделением) при заданном температурном напоре $\Delta T=T_{s t}-T_{0}$ :

$$
K_{T}(t)=\left[P(t)-P_{w}(t)\right] /\left(\Delta T S_{w}\right),
$$

где $S_{w}-$ площадь поверхности зонда, $P_{w}-$ тепловыделение, затраченное на нагрев собственно зонда (оно оценивается по результатам опыта на воздухе при том же значении $\Delta T$ и разрежении $660 \mathrm{~Pa})$. При заданном значении $\Delta T(t)=$ const значения мощности $P(t)$ чувствительны к изменению интенсивности переноса тепла в серии опытов; чем выше значение $P(t)$, тем выше $K_{T}(t)$. В качестве примера на рис. 1 показаны результаты определения мощности $P(t)$, необходимой для поддержания заданного температурного напора, для компонентов изученных водных растворов.

Надежная повторяемость данных опыта в серии измерений и их чувствительность к малым изменениям свойств жидкости делают обоснованным переход к относительному варианту измерений. Исходя из задачи исследования опытные значения $K_{T}(t)$ приводились к безразмерному виду

$$
\Delta K_{T} / \bar{K}_{T}=2\left(K_{T \text { add }}-K_{T \text { exp }}\right) /\left(K_{T 0}+K_{T 100}\right),
$$

где нижние индексы $a d d$ и $\exp$ обозначают аддитивные и экспериментальные значения, 0 и 100 - значения исходных компонентов соответственно.
Опыты по сопоставлению тепловой проводимости импульсно перегретых растворов были проведены на 14 системах в полном интервале концентраций. Водным растворам гликолей свойственны отрицательные значения, а растворам ФОЖ с углеводородами - большие положительные значения $v^{E}$. Опыты проведены при значениях $T_{s t}=363,393$ и $423 \mathrm{~K}$.

Исходная температура $T_{0}$ составляла $298 \mathrm{~K}$. Длина зонда была равна $9 \mathrm{~mm}$, его диаметр - $20 \mu \mathrm{m}$. Продолжительность нагрева была выбрана равной $10 \mathrm{~ms}$. Такая продолжительность, с одной стороны, обеспечивает достаточную толщину прогретого слоя, с другой - в несколько раз меньше интервала времени, необходимого для „включения“ механизма конвективного теплообмена [11]. В качестве примера на рис. 2 показаны результаты для водных растворов гомологов ППГ. Они свидетельствуют о появлении дополнительного теплового сопротивления относительно аддитивных значений тепловой проводимости для всех изученных значений концентрации и температуры в опыте. Эти результаты были получены в области устойчивых состояний раствора (системы $1-3$ при $363 \mathrm{~K}$ ) и не вполне устойчивых состояний, перегретых относительно $T_{s}$ (системы $1-3$ при $393-423 \mathrm{~K}$ и содержании воды $c>0.5)$ или $T_{l l}$ (система 4 при $363-423 \mathrm{~K}, c>0.5$, см. подробнее в работе [4]).

В целом подобный результат был получен для всего массива растворов, в том числе для растворов с нижней критической температурой растворения, во всем изученном интервале температур. На рис. 3 обобщены опытные данные для максимальных значений $\Delta K_{\mathrm{T}} / \bar{K}_{\mathrm{T}}$ $\left(T_{s t}=423 \mathrm{~K}\right)$ этих растворов и оценки максимальных значений их объема смешения $v_{\max }^{E}(c \sim 0-1)$ при температуре $T_{0}=298 \mathrm{~K}$ (системы $\left.1-10\right), 303 \mathrm{~K}$ (си-

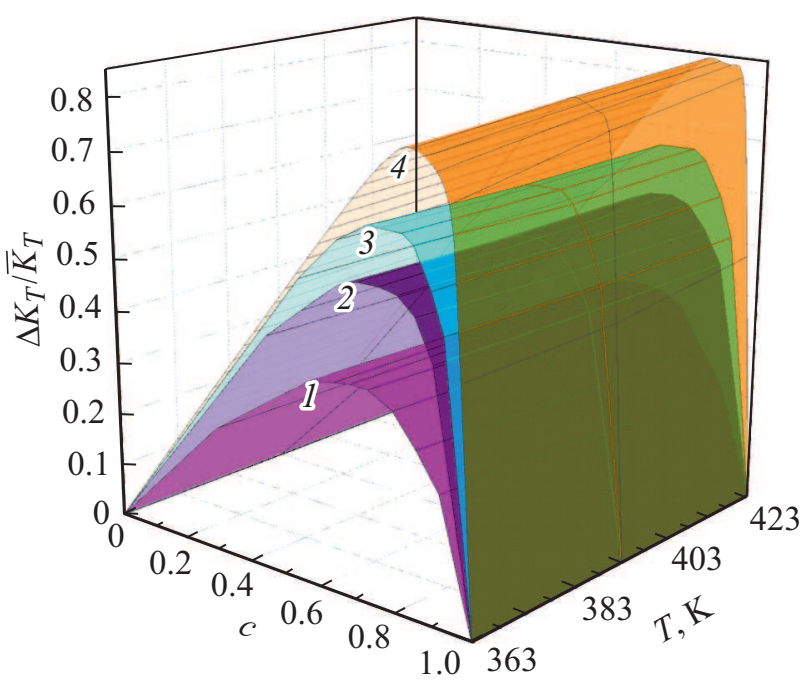

Рис. 2. Отклонение аддитивных значений коэффициента тепловой проводимости от результатов опыта (соотношение (2)) в зависимости от температуры и содержания воды $c$ в растворах: 1 - монопропиленгликоля; 2 - дипропиленгликоля; 3 - трипропиленгликоля; 4 - ППГ-425. 


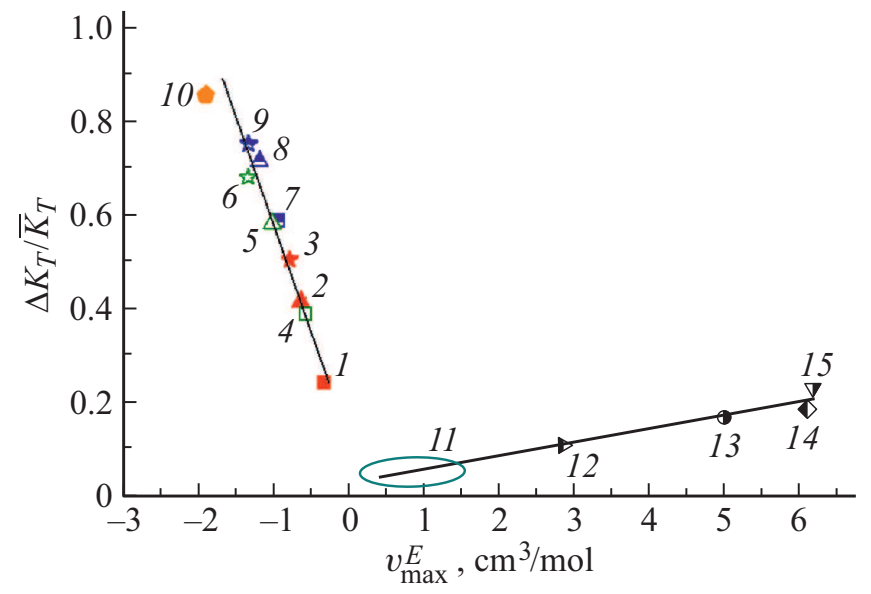

Рис. 3. Корреляция значений максимумов отклонения концентрационной зависимости приведенной тепловой проводимости растворов при температуре $T_{s t}(t)=423 \mathrm{~K}$ и максимумов их объемов смешения. 1 - этиленгликоль; 2 - диэтиленгликоль; 3 - триэтиленгликоль; 4 - пропиленгликоль; 5 - дипропиленгликоль; 6 - трипропиленгликоль; 7 - ПЭГ-200; 8 - ПЭГ-400; 9 - ПЭГ-600; $10-$ ППГ-425; 11 - данные по теплопроводности $[7,8] ; 12$ - октофторбутилдигидрат-гексен; 13 - перфтороктан-гексан; 14 - перфторметилциклогексан-гексен; 15 -перфтор|диметилциклогексан-гексен.

стемы 12-14) и $333 \mathrm{~K}(15)$. Значения отрицательного отклонения концентрационной зависимости тепловой проводимости водных растворов и растворов ФОЖ составили $0.2-0.8$ и $0.1-0.2$ соответственно. В итоге результаты работ [7,8] экспериментально дополнены новым материалом, основанным на существенном расширении области изменения значений $v^{E}$ и $T$, включая не вполне устойчивые состояния. Полученные данные окажутся полезными для уточнения причин появления „дополнительного теплового сопротивления“ в растворах и степени общности этого явления.

\section{Финансирование работы}

Исследование выполнено при финансовой поддержке Российского научного фонда в рамках научного проекта № 19-19-00115.

\section{Конфликт интересов}

Авторы заявляют, что у них нет конфликта интересов.
[3] I.M. Abdulagatov, A.R. Bazaev, E.A. Bazaev, B.K. Osmanova, J. Mol. Liq., 323, 114649 (2021). DOI: 10.1016/j.molliq.2020.114649

[4] A.A. Igolnikov, S.B. Rutin, P.V. Skripov, Thermochim. Acta, 695, 178815 (2021). DOI: 10.1016/j.tca.2020.178815

[5] I.A. Kozulin, V.V. Kuznetsov, J. Phys.: Conf. Ser., 1359 (1), 012052 (2019). DOI: 10.1088/1742-6596/1359/1/012052

[6] В.М. Чудновский, В.И. Юсупов, Письма в ЖТФ, 46 (20), 31 (2020). DOI: 10.21883/PJTF.2020.20.50153.18426 [V.M. Chudnovskii, V.I. Yusupov, Tech. Phys. Lett., 46 (10), 1024 (2020). DOI: 10.1134/S1063785020100211].

[7] Л.П. Филиппов, С.Н. Кравчун, ЖФХ, 56 (11), 2753 (1982).

[8] С.Н. Кравчун, ЖФХ, 60 (9), 2176 (1986).

[9] В.П. Скрипов, Мониторинг. Наука и технологии, № 3, 74 (2020).

[10] П.В. Скрипов, А.А. Старостин, Д.В. Волосников, ДАН, 390 (2), 192 (2003). [P.V. Skripov, A.A. Starostin, D.V. Volosnikov, Dokl. Phys., 48 (5), 228 (2003). DOI: 10.1134/1.1581317].

[11] S.B. Rutin, D.V. Volosnikov, P.V. Skripov, Int. J. Heat Mass Transf., 91, 1 (2015).

DOI: $10.1016 /$ j.ijheatmasstransfer.2015.07.001

\section{Список литературы}

[1] U. Hammerschmidt, W. Sabuga, Int. J. Thermophys., 21 (1), 217 (2000). DOI: 10.1023/A:1006621324390

[2] J.V. Sengers, Int. J. Thermophys, 41 (8), 117 (2020). DOI: $10.1007 / \mathrm{s} 10765-020-02696-7$ 